\title{
Evaluasi Pemantauan Intrapartum pada Persalinan dengan BBLR di RSUD Gunung Jati Kota Cirebon
}

\author{
Lisnawati \\ Jurusan Kebidanan, Politeknik Kesehatan Kemenkes Tasikmalaya \\ Email: bidan_lisna85@yahoo.com
}

\begin{abstract}
Evaluation of Midwives Skills in The Management of Labor with Low Birth Weight (LBW) (The study of intrapartum monitoring). Low Birth Weight (LBW) is neonates with birth weight less than 2,500 grams (up to 2,499 grams) without looking the duration of pregnancy. LBW is one cause of infant mortality rate in Indonesia. Increasing the knowledge, attitudes, and skills of midwives are the strategy to reduce infant mortality rate. The number of spontaneous labor with preterm gestation by midwives is the main reason to increase the skills of the LBW. This study was aimed to evaluate the skills of midwives in the management of labor with low birth weight in intrapartum monitoring. The methods were a quantitative and qualitative study with cross sectional approach. The quantitative was to evaluate the skills of midwives in intrapartum monitoring (active phase of the first stage), it is using checklists to 20 midwives in the delivery room who had received at least 1 case of labor with LBW. Research also conducted qualitatively by interviewing midwives in the delivery room and hospital managers. The results of this study showed that the midwives were not competent in the intrapartum monitoring of LBW. The average value of midwives skills in action intrapartum monitoring is $70.3 \%$ (the highest value is $81,25 \%$ and the lowest is $62,25 \%$ ). The midwives know that labor with LBW is not authorized by midwives, all this time management labor with low birth weight is through a doctor's advice, but the midwives were not competent and not confident in providing care in the management of labor with LBW. This study showed that the skills of midwives in the intrapartum monitoring of LBW are not good enough to be able to reduce mortality due to LBW.
\end{abstract}

Keywords: Intrapartum monitoring, Low Birth Weight

\begin{abstract}
Abstrak: Evaluasi Pemantauan Intrapartum pada Persalinan dengan BBLR di RSUD Gunung Jati Kota Cirebon. Bayi Berat Lahir Rendah (BBLR) adalah neonatus dengan berat badan lahir kurang dari 2.500 gram (sampai 2.499 gram), tanpa memandang lama masa kehamilan dan merupakan salah satu penyebab kematian bayi di Indonesia. Peningkatan pengetahuan, sikap dan keterampilan bidan, merupakan upaya dalam menurunkan angka kematian bayi. Banyaknya persalinan spontan dengan usia kehamilan prematur yang ditolong oleh Bidan menjadi dasar perlunya peningkatan keterampilan mengenai BBLR. Penelitian ini bertujuan untuk mengevaluasi keterampilan bidan dalam pengelolaan persalinan dengan BBLR dalam pemantauan intrapartum. Penelitian ini adalah penelitian deskriptif dengan menggunakan teknik kuantitatif dan kualititaif. Pada teknik kuantitatif, variabel keterampilan bidan dalam pemantauan intrapartum (kala I fase aktif), menggunakan daftar tilik kepada 20 orang bidan di ruang bersalin yang pernah mendapatkan minimal 1 kasus persalinan dengan BBLR. Pada penelitian kualitatif, dilakukan wawancara pada bidan di ruang bersalin dan manager Rumah Sakit terkait. Hasil penelitian menunjukkan bahwa bidan tidak terampil dalam pemantauan intrapartum pada persalinan dengan BBLR. Nilai rata-rata keterampilan bidan dalam melakukan tindakan pemantauan intrapartum adalah $70,3 \%$ (nilai tertinggi adalah $81,25 \%$ dan terendah 62,25\%). Bidan mengetahui bahwa persalinan BBLR bukan kewenangan bidan, selama ini penatalaksanaan persalinan dengan BBLR adalah melalui advis dokter, namun bidan merasa belum kompeten dan belum percaya diri dalam memberikan asuhan pada pengelolaan persalinan dengan BBLR. Penelitian ini menunjukkan keterampilan bidan dalam pemantauan intrapartum pada kasus persalinan dengan BBLR belum cukup baik untuk dapat menurunkan angka kematian akibat BBLR.
\end{abstract}

Kata kunci: Pemantauan Intrapartum, Persalinan dengan BBLR

Masa yang paling rentan dari sepanjang kehidupan bayi adalah periode neonatal $(0-28$ hari). Dari periode neonatal, masa yang paling rentan adalah ketika bayi berumur 0-6 hari (neonatal dini), yaitu kondisi bayi baru lahir sangat dipengaruhi oleh faktor biologis (kondisi janin ketika di dalam kandungan) dan faktor luar yaitu manajemen pada persalinan dan penanganan bayi baru lahir sangat mempengaruhi kelangsungan hidup bayi baru lahir (Sarimawar, 2007). 
Prevalensi bayi berat lahir rendah (BBLR) diperkirakan $15 \%$ dari seluruh kelahiran di dunia dengan batasan 3,3\%-3,8\% dan lebih sering terjadi di negara-negara berkembang. Secara statistik menunjukkan $90 \%$ kejadian BBLR didapatkan di negara berkembang dan angka kematiannya 35 kali lebih tinggi dibandingkan dengan bayi berat badan lebih dari 2500 gram (SDKI, 2012).

Angka Kematian Bayi (AKB) di Indonesia masih cukup tinggi bila dibandingkan dengan negara ASEAN (Assosiation of South East Asian Nation) lainnya. Berdasarkan Survey Demografi dan Kesehatan indonesia (SDKI) tahun 2012, AKB di Indonesia sebesar 32 per 1.000 kelahiran hidup. Di Indonesia dari seluruh kematian bayi, sebanyak $57 \%$ meninggal pada masa bayi baru lahir (usia di bawah 1 bulan) dan setiap 6 menit terdapat 1 bayi baru lahir yang meninggal. Pada tahun 2013, angka kejadian BBLR di Indonesia sebesar 10,2 \%. Penyebab kematian bayi baru lahir di Indonesia adalah BBLR (29\%), asfiksia (27\%) dan lain-lain $44 \%$.

Untuk mencapai penurunan AKB, salah satu rencana strategis Departemen Kesehatan (Renstra Depkes) yaitu meningkatkan akses pelayanan kesehatan yang berkualitas dan meningkatkan keterampilan petugas Kesehatan. Pengetahuan, sikap dan keterampilan petugas kesehatan, khususnya Bidan, merupakan upaya dalam menurunkan angka kematian bayi. Bidan yang memiliki pengetahuan, sikap dan keterampilan tentang BBLR diharapkan dapat menangani kasus BBLR dengan baik dan benar (Renstra Kemenkes RI, 2010).

Berdasarkan jurnal kebijakan kesehatan Indonesia tahun 2013, diketahui bahwa kinerja pelayanan KIA di Rumah Sakit Pemerintah Indonesia 66,3\% tidak optimal. Proporsi penanganan BBLR $<100 \%$, lebih banyak terjadi di Rumah Sakit kelas C (20,7\%) (Simbolon, 2013). Hasil penelitian kualitatif tentang Perilaku Bidan dalam menangani bayi asfiksia menunjukkan bahwa bidan kurang profesional disebabkan masih rendahnya pengetahuan dan keterampilan bidan, disamping faktor pemungkin seperti sarana dan prasarana yang tidak mendukung dan faktor penguat seperti peran pimpinan yang belum maksimal (Sunarti, 2008).

Masalah yang sering muncul pada BBLR adalah asfiksia, yaitu keadaan bayi yang tidak dapat bernapas spontan dan teratur segera setelah lahir, sehingga dapat menurunkan oksigen dan meningkatkan karbon dioksida yang dapat menimbulkan akibat buruk dalam kehidupan yang lebih lanjut (Pedro, 2011). Seringkali bayi yang sebelumnya mengalami gawat janin akan mengalami asfiksia sesudah persalinan, sehingga membutuhkan tindakan resusitasi setelah bayi lahir (Fauchere, 2012). Kualitas pemantauan intrapartum sangat diperlukan untuk mengurangi kejadian gawat janin. (Walther, 2007).

Faktor risiko kematian neonatal bersifat ganda termasuk BBLR. Bukan hanya penyebab langsung kematian, tetapi juga merupakan faktor utama yang mengancam kesempatan bayi baru lahir untuk bertahan hidup. (Culhane, RL 2007) BBLR yang diperkirakan $15 \%$ dari kelahiran hidup di seluruh dunia, mencakup negara maju sebesar 6\% dan negara berkembang sebesar 30\%. Meskipun hanya $14 \%$ bayi dengan BBLR dilahirkan di negara berkembang, jumlah ini bertanggung jawab terhadap 60\%-80\% kematian neonatal (Yanti, 2014).

Angka Kematian Bayi di kota Cirebon tahun 2013 sebanyak 39 bayi. Penyebab kematian bayi terbanyak yaitu 19 bayi meninggal karena BBLR (48,7\%), Asfiksia $(12,8 \%)$ dan lain-lain $(38,5 \%)$ (Profil Dinkes Kota Cirebon, 2013).

Berdasarkan survey pendahuluan yang dilakukan di Rumah Sakit Umum Daerah (RSUD) Gunung Jati Kota Cirebon periode bulan Januari sampai dengan bulan Desember tahun 2014, terdapat 1.958 persalinan dengan 369 $(18,8 \%)$ diantaranya adalah persalinan dengan Bayi Berat Lahir Rendah (BBLR), dan total kematian neonatal dini akibat BBLR adalah sebanyak 17 bayi meninggal setelah lahir. Dari 17 kasus kematian neonatal dini, 13 diantaranya ditolong oleh bidan, sedangkan 4 kasus persalinan dengan BBLR lainnya ditolong oleh Dokter Spesialis kandungan (Laporan Persalinan RSUD Gunung Jati, 2013).

Fenomena yang terjadi di Rumah Sakit Umum Daerah adalah semua persalinan spontan baik pada usia kehamilan aterm maupun prematur ditolong oleh Bidan. Berdasarkan hasil studi pendahuluan yang peneliti lakukan melalui wawancara terhadap beberapa bidan di RSUD Gunung Jati Kota Cirebon, dari 20 orang bidan, 5 orang $(25 \%)$ telah mengikuti pelatihan tentang penanganan asfiksia pada bayi baru lahir, sedangkan 15 orang lainnya $(75 \%)$ belum melakukan pelatihan. Hal ini berdampak pada keterampilan bidan tentang pengelolaan persalinan dengan BBLR. Pelatihan dapat mempengaruhi keterampilan seseorang disamping faktor umur, pendidikan ataupun lamanya bekerja sebagai bidan (Endang S, 2012). Salah satu cara untuk menurunkan AKB adalah melalui tenaga kesehatan, terutama bidan yang kompeten, untuk mengetahuinya, perlu dilakukan evaluasi (AIPKIN Id, 2011). 


\section{METODE}

Penelitian ini adalah penelitian deskriptif dengan menggunakan teknik kuantitatif dan kualitatif. Pada teknik kuantitatif, untuk variabel keterampilan bidan dalam pemantauan intrapartum pada kala I fase aktif dengan BBLR, penelitian menggunakan data primer pada 20 bidan di ruang bersalin, dengan cara observasi menggunakan daftar tilik. Setiap bidan mendapatkan 1 kasus yaitu persalinan dengan BBLR kemudian melakukan pemantauan intrapartum pada kala I fase aktif.

Pada teknik kualitatif, penelitian menggunakan data primer dengan cara wawancara pada seluruh bidan di ruang bersalin dan para stakeholder (6 orang) tentang pengelolaan persalinan dengan BBLR di RSUD Gunung Jati Kota Cirebon.

Kriteria inklusi sebagai berikut: a) Bidan pelaksana di ruang bersalin b) Berpendidikan minimal D.III Kebidanan. c) Kasus yang diambil adalah persalinan yang diduga BBLR dengan janin hidup, taksiran berat janin <2500 gram, umur ibu bersalin 20-35 tahun, tidak memiliki penyakit hipertensi, TBC, infeksi dan Diabetes Mellitus, persalinan spontan ditolong oleh bidan.
Kriteria ekslusi penelitian ini adalah: bidan yang tidak hadir saat dilakukan penelitian. Variabel Kuantitaif yaitu: a) Keterampilan bidan dalam pemantauan intrapartum kala I fase aktif pada ibu bersalin dengan BBLR, yang dinilai dengan menggunakan daftar tilik yang dibagi menjadi 2 kategori yaitu kompeten dan tidak kompeten. Pada variabel kualitatif, yaitu tentang pengelolaan persalinan dengan BBLR yang ada di RSUD Gunung Jati kota Cirebon. Pengolahan data kuantitatif dilakukan pada data yang telah diperoleh melalui proses pengolahan data yaitu editing, coding, processing dan cleaning, kemudian data dideskripsikan (Arikunto, 2006). Pengelolaan data kualitatif yang terkumpul melalui wawancara mendalam yang diajukan dengan pertanyaan terbuka akan dilakukan analisis dan kualifikasi terhadap jawaban yang diberikan secara interaktif, yaitu setelah data terkumpul dibuat ringkasan, pengkodean dan membuat catatan kaki, membuang yang tidak perlu, untuk selanjutnya data disajikan dalam bentuk teks naratif.

Penelitian dilakukan di RSUD Gunung Jati kota Cirebon pada bulan Mei sampai September 2015.

\section{HASIL}

\section{A. ANALISIS KUANTITATIF}

Tabel 1. Keterampilan Bidan dalam Pemantauan Intrapartum Kala I Fase Aktif pada Persalinan dengan BBLR

\begin{tabular}{|c|c|c|c|c|c|c|c|c|c|c|c|c|}
\hline \multirow[b]{2}{*}{ No. } & \multicolumn{7}{|c|}{ Prosedur } & \multirow[b]{2}{*}{ N.T $\left(\sum=16\right)$} & \multirow[b]{2}{*}{$\%$} & \multirow[b]{2}{*}{ X8 } & \multirow[b]{2}{*}{ X9 } & \multirow[b]{2}{*}{ X10 } \\
\hline & $\begin{array}{c}X 1 \\
M=5\end{array}$ & $\begin{array}{c}\mathrm{X} 2 \\
\mathrm{M}=1\end{array}$ & $\begin{array}{c}\mathrm{X3} \\
\mathrm{M}=1\end{array}$ & $\begin{array}{l}X 4 \\
M=1\end{array}$ & $\begin{array}{c}X 5 \\
M=4\end{array}$ & $\begin{array}{c}\mathrm{X6} \\
\mathrm{M}=1\end{array}$ & $\begin{array}{c}\mathbf{X} 7 \\
\mathbf{M}=3\end{array}$ & & & & & \\
\hline 1 & 3 & 0 & 0 & 1 & 3 & 0 & 3 & 10 & 62,5 & 25 & D. 3 & 1 \\
\hline 2 & 3 & 0 & 0 & 1 & 2 & 1 & 3 & 10 & 62,5 & 25 & D. 3 & 1 \\
\hline 3 & 3 & 0 & 0 & 1 & 3 & 1 & 3 & 11 & 68,75 & 23 & D. 3 & 1 \\
\hline 4 & 3 & 1 & 1 & 1 & 2 & 1 & 3 & 12 & 75 & 24 & D. 3 & 1 \\
\hline 5 & 3 & 0 & 0 & 1 & 3 & 1 & 3 & 11 & 68,75 & 24 & D.3 & 1 \\
\hline 6 & 3 & 1 & 1 & 1 & 2 & 1 & 3 & 12 & 75 & 24 & D. 3 & 1 \\
\hline 7 & 3 & 1 & 1 & 1 & 2 & 1 & 3 & 12 & 75 & 31 & D. 3 & 4 \\
\hline 8 & 3 & 0 & 0 & 1 & 2 & 1 & 3 & 10 & 62,5 & 51 & D.3 & 25 \\
\hline 9 & 3 & 1 & 1 & 1 & 2 & 1 & 3 & 12 & 75 & 50 & D.3 & 25 \\
\hline 10 & 3 & 0 & 0 & 1 & 3 & 1 & 3 & 11 & 68,75 & 25 & D. 4 & 2 \\
\hline 11 & 3 & 1 & 1 & 1 & 3 & 1 & 3 & 13 & 81,25 & 43 & D. 4 & 15 \\
\hline 12 & 3 & 1 & 1 & 1 & 3 & 1 & 3 & 13 & 81,25 & 24 & D. 3 & 1 \\
\hline 13 & 3 & 0 & 0 & 1 & 2 & 1 & 3 & 10 & 62,5 & 24 & D. 3 & 1 \\
\hline 14 & 3 & 0 & 0 & 1 & 2 & 1 & 3 & 10 & 62,5 & 28 & D. 3 & 3 \\
\hline 15 & 3 & 0 & 0 & 1 & 3 & 1 & 3 & 11 & 68,75 & 32 & D. 3 & 4 \\
\hline 16 & 3 & 1 & 1 & 1 & 3 & 1 & 3 & 13 & 81,25 & 50 & D. 4 & 25 \\
\hline 17 & 3 & 0 & 0 & 1 & 3 & 1 & 3 & 11 & 68,75 & 28 & D. 3 & 3 \\
\hline 18 & 3 & 0 & 0 & 1 & 2 & 1 & 3 & 10 & 62,5 & 32 & D. 3 & 4 \\
\hline 19 & 3 & 1 & 1 & 1 & 3 & 1 & 3 & 12 & 75 & 43 & D. 4 & 15 \\
\hline 20 & 3 & 0 & 0 & 1 & 3 & 1 & 3 & 11 & 68,75 & 43 & D. 3 & 15 \\
\hline $\mathbf{X}$ & 3 & 0,4 & 0,4 & 1 & 2,6 & $\mathbf{0 , 9 5}$ & 3 & 11,25 & 70,3 & & & \\
\hline
\end{tabular}




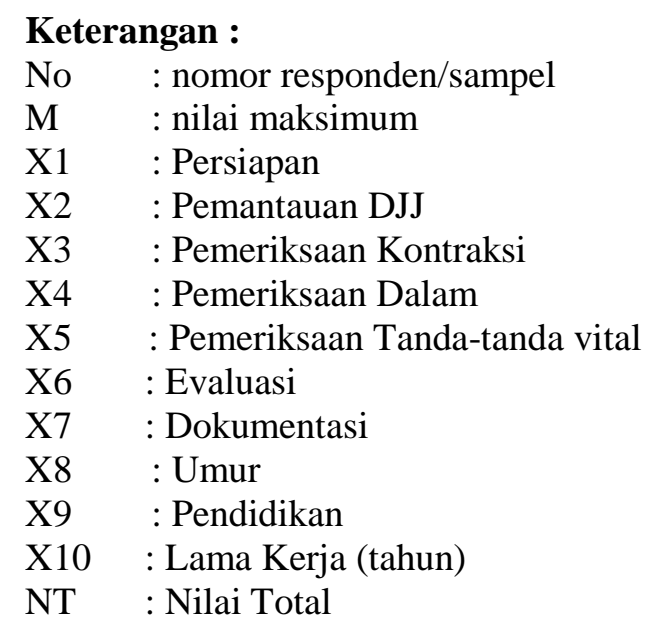

Nilai rata-rata keterampilan bidan dalam melakukan pemantauan intrapartum kala I fase aktif pada persalinan dengan BBLR adalah $70,3 \%$ (nilai rata-rata tertinggi adalah $81,25 \%$ dan terendah $62,5 \%$ ). Semua bidan melakukan pemeriksaan dalam, mengevaluasi dan mendokumentasikan dengan benar. Usia bidan mulai dari 23-51 tahun. Pendidikan terendah adalah D.3 kebidanan (16 orang) dan tertinggi D.4 kebidanan (4 orang). Masa kerja mulai dari 1 tahun-25 tahun. Temuan ketidaksesuaian dalam pelaksanaan pemantauan intrapartum pada BBLR yaitu:

1. Tahap persiapan :

a) Tidak memperhatikan kontrol suhu ruangan (saat persalinan, suhu ruangan bersalin tetap dingin atau $<25^{\circ} \mathrm{C}$ )

b) Tidak menyalakan infarm warmer (minimal 15 menit sebelum dilakukan pertolongan persalinan)

2. Pemeriksaan denyut jantung janin dan kontraksi hanya dilakukan 1 kali pada saat di awal pemeriksaan

3. Pemeriksaan tanda-tanda vital: tidak melakukan pemeriksaan nadi, respirasi dan suhu, hanya dilakukan pemeriksaan tekanan darah.

\section{B. ANALISIS KUALITATIF}

\section{Kewenangan Bidan dalam Pengelolaan Persalinan dengan BBLR}

Terbatasnya keterampilan yang dimiliki oleh bidan, terutama dalam pengelolaan BBLR merupakan salah satu kendala rendahnya kualitas pelayanan kebidanan yang diberikan. Fenomena di rumah sakit umum adalah seluruh persalinan spontan ditolong oleh bidan termasuk persalinan dengan BBLR. Namun, tidak semua bidan kompten dalam melakukan pertolongan persalinan dengan BBLR, maka hal ini perlu dipertanyakan.
"Kalau menurut saya dari tugas dan wewenang bidan, persalinan BBLR itu kan termasuk dengan penapisan ya, kalau praktik di rumah, memang tidak boleh, tapi karena lingkungan kerja kita rumah sakit, itu kan ada yang lebih, dokter jaganya atau penanggng jawab dari bidang maternal nya ya, jadi kalau di VK itu kan ada dokter jaga, jadi ya sesuai dengan anjuran dokter kalau misalkan kira-kira inimah masuk partus normal, yang penting persiapan alat lengkap, trus bayinya tidak berisiko, boleh ditolong oleh bidan. tapi kalau misalnya bayinya sudah BBLR, ibunya kehamilannya preterm tapi misalkan dengan kelainan jantung, hipertensi mungkin itu beda lagi ceritanya, jadi yang BBLR nya yang dilahirkan dari ibu yang gak ada komplikasi, tapi kalau ada komplikasi itu beda lagi." (R.8)

Namun ada pula bidan yang berpendapat bahwa bidan sebaiknya tidak melakukan pertolongan persalinan dengan BBLR karena banyaknya risiko yang dihadapi bidan. Berikut kutipan wawancaranya :

"Kalau dilihat dari undang-undang ya bukan, karena berat badan lahir rendah ini kan resiko, walaupun terkadang setelah dilahirkan tidak tampak kelainan-kelainannya ya, tapi kalau setelah beberapa jam, beberapa hari atau beberapa minggu baru keliatan, jadi sebaiknya oleh dokter obgyn dan spesialis anak." (R.8)

\section{Protap Penanganan Persalinan dengan BBLR}

Menurut Kamus Besar Bahasa Indonesia, prosedur tetap atau protap adalah tindakan yang harus dijalankan dengan cara yang sama agar selalu memperoleh hasil yang sama dari kejadian yang sama. Di RSUD Gunung Jati Cirebon, protap tentang penatalaksanaan persalinan dengan BBLR tidak ada. Selama ini pelaksanaannya adalah dengan melakukan konsultasi ke dokter, dan melakukan pemantauan keadaan ibu dan bayi, bila bayi fetal dystress maka selalu dipantau dengan CTG, peralatan kegawatdaruratan sudah siap, jika instruksi dokter partus pervaginam, maka penolong adalah bidan. Salah satu kutipannya sebagai berikut:

"Kalau protap khusus tentang persalinan BBLR di VK gak ada, Ya, kalau BBLR di kita, di rumah sakit itu, kalau memang intrapartumnya normal, maksudnya...eee... DDJ baik, itu kan kita penatalaksanaan asuhan yang biasa, tapi kalau memang ...eeee..distress dan itu mungkin pemantauan ketat terhadap ibu dan bayi. Kalau memang distress kita pantau dengan memasang CTG walaupun itu awal kita rekam, selanjutnya 
kita rekam tapi tidak di print, kita pantau stand by di sana." (R.5)

\section{Penilaian tentang Kompetensi Diri dalam Penanganan Persalinan dengan BBLR}

Beberapa Bidan di Rumah Sakit Gunung

Jati Cirebon pernah mengikuti pelatihan tentang resusitasi BBLR yang diselenggarakan mandiri oleh pihak rumah sakit, namun mereka tetap merasa belum kompeten dalam menangani kasus pengelolaan persalinan dengan BBLR, terutama kasus resusitasi pada BBLR. Salah satu kutipan wawancara sebagai berikut :

"Gimana ya..kalau menolong persalinan dengan BBLR itu kan bukan kewenangan bidan, tapi disini kan rumah sakit rujukan, bidan harus punya keterampilan tentang kegawatdaruratan. Jadi Rumah sakit memberikan pelatihan juga kepada bidan disini. Untuk tindakan resusitasi BBLR itu yang dirasa sangat sulit, kayanya walaupun sudah pelatihan juga masih merasa kurang mampu, itu kan kegawatdaruratan. waktu pelatihan juga kan latihannya ke phantoom jadi tetap merasa sangat berbeda dengan kenyataannya”.(R.5)

\section{Alasan Bidan Menolong Persalinan dengan BBLR}

Rumah Sakit memiliki aturan bahwa persalinan normal ditolong oleh bidan, dengan dokter sebagai penanggung jawabnya, termasuk persalinan dengan BBLR, namun bidan belum percaya diri dalam melakukan pengelolaan persalinan dengan BBLR terutama pada kasus resusitasi BBLR.

"Eeeee....gimana ya saya kan disini bekerja di rumah sakit rujukan, jadi di sini kasusnya nggak hanya yang fisiologis aja, tapi yang patologis juga banyak. khusus untuk persalinan dengan BBLR di rumah sakit ini, selama ini ya kita mengikuti saja aturan yang ada disini. kalau partus normal kan oleh bidan, bearti kalau BBLR juga kalau lahirannya normal ya dengan bidan. Kita mau nggak mau ya harus bisa, makanya bidan disini dilatih. paling kita kalau ada apaapa ya konsul dengan dokternya, kita juga bertindak atas instruksi dokter. Kalau percaya diri sih kayanya kalau kasusnya udah sering kita tangani ya percaya diri, kalau belum pernah ya pasti takut juga. resusitasi BBLR nggak sebanyak yang bukan BBLR, tapi selama ini kita berusaha untuk belajar".(R.5)

\section{Kebijakan tentang Pertolongan Persalinan dengan BBLR}

Selama ini, belum ada protap atau aturan khusus tentang pengelolaan persalinan dengan
BBLR. Aturan yang sudah berjalan adalah bidan selalu melaporkan hasil observasi pasien di ruang bersalin kepada dokter kandungan yang jaga saat itu, maka tindakan yang akan dilakukan sesuai dengan advis dokter. Bila keadaan janin baik dan bisa lahir spontan, maka persalinan ditolong oleh bidan. Hal ini berdasarkan salah satu kutipan berikut:

"Selama ini kita pakai protap umum yang sudah ada, kita masih terus melakukan perbaikan." (R.2)

"Sesuai dengan SOP penanganan persalinan, bidan tetap melaporkan ke dokter jaga. Setiap hari selalu ada visit dokter jaga. Selalu diobservasi, apakah bisa partus pervaginam atau harus SC." (R.3)

\section{PEMBAHASAN}

\section{Keterampilan Bidan dalam Pemantauan Intrapartum}

Berdasarkan tabel 1, nilai rata-rata keterampilan bidan dalam melakukan pemantauan intrapartum kala I fase aktif adalah $70,3 \%$ (nilai rata-rata tertinggi adalah $81,25 \%$ dan terendah $62,25 \%$ ). Semua bidan melakukan pemeriksaan dalam, mengevaluasi dan mendokumentasikan dengan benar. Usia bidan mulai dari 23-51 tahun. Pendidikan terendah adalah D.3 kebidanan (16 orang) dan tertinggi D.4 kebidanan (4 orang). Masa kerja mulai dari 1 tahun-25 tahun.

Temuan ketidaksesuaian dalam pelaksanaan pemantauan intrapartum pada BBLR yaitu: tahap persiapan (tidak memperhatikan kontrol suhu ruangan (suhu ruangan bersalin tetap dingin), tidak menyalakan infant warmer (minimal 15 menit sebelum dilakukan pertolongan persalinan), pemeriksaan denyut jantung janin dan kontraksi hanya dilakukan 1 kali pada saat di awal pemeriksaan, pemeriksaan tanda-tanda vital (tidak melakukan pemeriksaan nadi, respirasi dan suhu).

Pada kolom X1 (persiapan) menunjukkan bahwa semua bidan memiliki nilai yang sama yaitu 3 (nilai maksimum adalah 5). Hasil observasi menggunakan daftar tilik diketahui bahwa semua bidan tidak menyiapkan suhu ruang bersalin dan infant warmer (minimal 15 menit sebelum kala II). Salah satu penyebab tidak dilakukannya persiapan suhu ruang karena tidak adanya SOP (standard operating procedures) atau prosedur tetap tentang pengelolaan persalinan dengan BBLR khususnya pada pemantauan intrapartum. SOP berfungsi membentuk sistem kerja dan aliran kerja yang 
teratur, sistematis dan dapat dipertanggungjawabkan, menjelaskan bagaimana proses pelaksanaan kegiatan berlangsung (Sumiati, 2013). Persiapan ruang bersalin yaitu dengan memastikan ruang persalinan tetap hangat (tidak dingin karena adanya penggunaaan AC, sehingga bidan perlu memantau berapa suhu ruangan saat itu, atau matikan AC bila perlu. Sama halnya dengan persiapan infant warmer, semua bidan tidak menyalakan dulu infant warmer sebelum bayi dilahirkan. Infant warmer dinyalakan saat mulai melakukan asuhan pada bayi baru lahir, atau saat bayi dibawa ke ruang resusitasi bayi baru lahir. Pengaturan suhu ruang dan infant warmer sangat penting untuk dilakukan, karena BBLR mudah mengalami hipotermi, yang dapat mengganggu stabilitas suhu pada BBLR (Group NR, 2014).

Pada kolom X2 (pemantauan DJJ) menunjukkan bahwa 12 orang bidan mendapatkan nilai 0 (tidak melakukan pemantauan DJJ), dan siasanya 8 orang bidan mendapakan nilai 1 (melakukan pemantauan DJJ). Pada tindakan pemantauan Denyut Jantung Janin pada pasien inpartu dengan BBLR, pada kala I fase aktif seharusnya dilakukan setiap 30 menit sekali. Denyut Jantung Janin didengar selama 1 menit, kemudian dilakukan penilaian apakah bayi dalam keadaan normal atau fetal dystress (gawat janin). Janin yang tidak dipantau berarti mengurangi upaya pencegahan terjadinya fetal dystress atau asfiksia pada BBLR, hal ini dapat memperberat dan menimbulkan komplikasi pada BBLR, yang pada akhirnya dapat mengakibatkan terjadinya IUFD atau asfiksia berat. Berbeda dengan pemantauan DJJ pada persalinan normal, untuk persalinan dengan BBLR dengan risiko gawat janin yang lebih tinggi, maka pemantauan DJJ dilakukan dengan lebih intensif,salah satunya dengan memasang CTG agar denyut jantung janin bisa terus dipantau (Kathrine, 2009).

Pada kolom X3 (pemantauan kontraksi), diketahui bahwa 12 orang bidan mendapatkan nilai 0 (tidak melakukan pemantauan kontraksi) dan sisanya 8 orang bidan mendapatkan nilai 1 (melakukan pemantauan kontraksi). Pemantauan kontraksi atau his, diperiksa selama 10 menit, kemudian dilihat berapa frekuensi, intensitas dan amplitudonya. Hal ini penting dilakukan karena kontraksi dinilai untuk mengetahui kemajuan persalinan. Kontraksi juga dapat berpengaruh pada kondisi janin, misalnya pada kasus kontraksi atau his hipertonik dapat mengakibatkan janin kekurangan oksigen, dan bisa menyebabkan asfiksia neonatorum. Pemanatauan kontraksi yang tepat dan benar pada persalinan dengan BBLR dapat mengurangi komplikasi pada bayi baru lahir (Prawirohardjo, 2006).

Pada kolom X4 (pemeriksaan dalam), semua bidan mendapatkan nilai 1 (melakukan pemeriksaan dalam). Hal ini karena pemeriksaan dalam merupakan salah satu pemeriksaan penentu dalam menentukan diagnosa pasien. Pemeriksaan dalam pada pemantauan persalinan sangat penting dilakukan untuk menilai kemajuan persalinan dan tindakan yang harus dilakukan. Dalam pemantauan persalinan dengan BBLR, bidan melakukan pemeriksaan dalam sesuai dengan instruksi dokter.

Pada kolom X5 (pemantauan tanda-tanda vital), tidak ada bidan yang memperoleh nilai maksimal, 11 orang bidan mendapatkan nilai 3 dan sisanya, 9 orang bidan mendapatkan nilai 2 . Pada pemeriksaan tanda-tanda vital, semua bidan melakukan pemeriksaan tekanan darah, namun untuk pemeriksaan nadi, respirasi dan suhu tidak semua dilakukan. Hasil observasi menggunakan daftar tilik menunjukkan semua bidan tidak melakukan pemeriksaan pernapasan, hal ini karena kebiasaan bidan dalam melakukan pemeriksaan tanda-tanda vital, hanya pada tekanan darah, nadi dan suhu. Pemeriksaan pernafasan dilakukan hanya pada kasus-kasus tertentu seperti pada ibu dengan pre eklampsi atau eklampsi.

Pada kolom X6 (evaluasi) dan kolom X7 (dokumentasi), semua bidan melakukan mendapatkan nilai maksimal (melakukan evaluasi dan dokumentasi). Evaluasi hasil pemeriksaan yaitu dengan mengkaji hasil pemeriksaan terhadap pasien dan melakukan kolaborasi dengan dokter dan memerikan asuhan sesuai instruksi dokter. Semua bidan di ruang bersalin sudah terbiasa untuk melakukan kolaborasi dengan dokter. Sesuai dengan SOP di ruang bersalin bahwa semua pasien yang masuk ke ruag bersalin harus berkolaborasi dengan dokter jaga. Pada tindakan dokumentasi, semua bidan mencatat respon klien selama dilakukan tindakan pemantauan persalinan. Pencatatan dilakukan dengan jelas, mudah dibaca, ditandatangani disertai nama jelas dan ditulis dengan bolpoin. Kegiatan evaluasi dan dokumentasi merupakan rutinitas bidan di ruang bersalin. Disebutkan dalam pasal 18 ayat (1) butir (h) Peraturan Menteri Kesehatan nomor 1464 tahun 2010 wujud kepatuhan bidan dalam menjalankan rekam medis adalah dengan melakukan pencatatan asuhan kebidanan dan pelayanan lainnya secara sistematis (Permenkes RI, 2010).

Nilai rata-rata keterampilan bidan dalam pemantauan intrapartum adalah $70,3 \%$, hal ini 
berarti tidak memenuhi syarat kompetensi dalam keterampilan yaitu $100 \%$. Hasil penelitian yang dilakukan AG Novika tahun 2013 menunjukkan bahwa kinerja bidan tidak baik $(47,5 \%)$ dalam pengelolaan BBLR.

Terdapat 3 bidan yang memiliki nilai tertinggi yaitu $81,25 \%$, yaitu pada responden nomor 11 (usia 43 tahun, pendidikan terakhir D.4 Kebidanan, dan masa kerja 15 tahun), responden nomor 12 (usia 24 tahun, pendidikan terakhir D.3 kebidanan, masa kerja 1 tahun), dan responden nomor 16 (usia 50 tahun, pendidikan terakhir D.4 kebidanan, masa kerja 25 tahun). Bidan yang memiliki nilai terendah yaitu $62,25 \%$ sebanyak 6 orang, dengan usia 25-51 tahun, seluruhnya berpendidikan terakhir D.3 Kebidanan, dan masa kerja 1-25 tahun.

Berdasarkan data tersebut, menunjukkan bahwa karakteristik bidan (usia, pendidikan terakhir dan masa kerja) pada nilai tertinggi dan terendah sangat bervariasi. Namun pada kelompok nilai terendah seluruh bidan berpendidikan terakhir D.3 Kebidanan. Penelitian kuantitatif yang dilakukan Santi DR pada tahun 2012, bahwa umur dan masa kerja berhubungan dengan kinerja bidan dalam tatalaksana BBLR.

Standar kompetensi bidan Indonesia, pada standar asuhan selama persalinan dan kelahiran menyebutkan bahwa "Bidan memberikan asuhan yang bermutu tinggi selama persalinan untuk mengoptimalkan kesehatan wanita dan bayinya yang baru lahir." Sehingga bidan sudah selayaknya kompeten pula dalam pemantauan intrapartum terutama pada kasus persalinan dengan BBLR.

Berdasarkan Kepmenkes nomor 369 tahun 2007 tentang standar profesi bidan dicantumkan bahwa pada kompetensi ke empat (landasan ilmiah praktik kebidanan), bidan memiliki pengetahuan yang diperlukan untuk memberikan asuhan yang berkualitas tinggi dan tanggap budaya selama persalinan, menolong persalinan dan kelahiran yang bersih dan aman serta menangani situasi kegawatdaruratan untuk memaksimalkan kesehatan ibu dan bayi, kompeten dalam pemantauan persalinan, pemantauan kesejahteraan janin, pemantauan kesejahteraan ibu. Salah satu upaya yang dapat dilakukan untuk menerapkan kompetensi bidan adalah dengan menerapkan standar operasional prosedur (SOP) untuk meningkatkan mutu pelayanan.

\section{SIMPULAN}

Hasil penelitian mengenai evaluasi keterampilan bidan dalam pengelolaaan persalinan dengan BBLR tentang pemantauan intrapartum dan resusitasi BBLR menunjukkan bahwa Bidan tidak terampil dalam pemantauan intrapartum (kala I fase aktif) pada persalinan dengan BBLR.

Bidan mengetahui bahwa persalinan BBLR bukan kewenangan bidan, selama ini penatalaksanaan persalinan spontan dengan BBLR dilakukan oleh bidan berdasarkan advis dokter, namun bidan merasa belum kompeten dan belum percaya diri dalam memberikan asuhan pada pengelolaan persalinan dengan BBLR.

\section{SARAN}

Penelitian ini dapat digunakan sebagai dasar untuk penelitian lebih lanjut khususnya tentang BBLR dan khusus untuk Rumah Sakit Umum Daerah, perlu adanya pelatihan untuk bidan tentang pengelolaan persalinan dengan BBLR di tingkat provinsi atau nasional, tidak hanya dilakukan mandiri oleh rumah sakit.

\section{DAFTAR PUSTAKA}

AIPKIN Id. 2011. Standar Kompetensi bidan Indonesia (revisi November 2011). Direktorat Jenderal Pendidikan Tinggi Kementerian Pendidikan dan Kebudayaan 2011.

Arikunto S. 2006. Prosedur Penelitian Suatu Pendekatan Praktik. Jakarta: Rineka Cipta.

Badan Pusat Statistik B, Kementerian Kesehatan. 2012. SDKI Tahun 2012. In: Indonesia DKR. Jakarta.
Culhane RL. 2007. Low Birth Weight in the United States. The American Journal of Clinical Nutrition.

Dinas Kesehatan Kotamadya Cirebon. 2013. Profil Kesehatan Kotamadya Cirebon.

Endang, S. 2012. Karakteristik Individu dan Karakteristik Organisasi Pengaruhnya Terhadap Motivasi dan Kinerja Bidan Pada Rumah Sakit Umum Pemerintah Daerah Tapal Kuda Jawa Timur 2012.

Fauchere, JC. 2012. Care and Resuscitation of the newborn infant. Pediatrics. 
Group, NR. 2014. Updating the Management of Preterm Infant in the 1st Min After Birth. Journal of Clinical Neonatology.

Kathrine, Leigh Peters RJR. 2009. Improvement Of Short and Long Term Outcomes for Very Low Birth Weight Infant: Edmonton NIDCP Trial. Pediatrics.

Kementerian Kesehatan Republik Indonesia. 2011. Peraturan Menteri Kesehatan Republik Indonesia Nomor 1464/MENKES/PER/2010 tentang izin dan Penyelenggaraan Praktik Bidan. Jakarta: Menteri Kesehatan Republik Indonesia.

Kementerian Keshatan Republik Indonesia. 2010. Rencana Strategis Kementerian Kesehatan Tahun 2010-2014. Keputusan Menteri Kesehatan RI Nomor HK.03.01/60/1/2010. Jakarta.

Pedro, R Coutinho JGC, Fernanda G Surita, Maria L Costa and Sirlei S Morais. 2011. Perinatal outcomes associated with Low Birth Weight in a historical cohort. Biomed Central.

Pedro, R Coutinho JGC, Fernanda G Surita, Maria L Costa and Sirlei S Morais. 2011. Perinatal Outcomes Associated with Low Birth Weight in a Historical Cohort. Biomed Central.

Prawirohadjo, S. 2006. Pelayanan Kesehatan Maternal dan Neonatal. Jakarta: YBP-SP.
RSUD Gunung Jati. 2013. Laporan Persalinan di RSUD Gunung Jati Kota Cirebon Tahun 2013. Cirebon.

Sarimawar, D. 2007. Trend of Stillbirth and Neonatal Mortality in Indonesia, Based on Health Survey Result Year 1995-2007.

Simbolon, Demsa, DC., Ernawati. 2013. Determinan Kinerja Pelayanan Kesehatan Ibu dan Anak di Rumah Sakit Pemerintah Indonesia. Jurnal Kebijakan Kesehatan Indonesia.

Sumiati, L. 2013. Pengaruh Penerapan Prosedur Kerja Terhadap Kinerja Bidan Desa dalam Pelayanan Kebidanan di Kabupaten Sukabumi Bandung. Thesis. Magister Kebidanan. Universitas Padjadjaran.

Sunarti, NN. 2008. Perilaku Bidan dalam Menangani Bayi Asfiksia Studi Kualitatif di RSUD Umbu Rara Waingapu Sumba Timur NTT.

Walther, F.J. 2007. A Randomised Controlled Trial of Delivery Room Respiratory Management in Very Preterm Infants. Pediatrics.

Yanti, E. 2014. Faktor-Faktor yang mempengaruhi Pengetahuan Bidan terhadap Penanganan Asfiksia pada Bayi Baru Lahir di RSU Cut Nyak Dhien Meulaboh Kabupaten Aceh Barat. 